\title{
Analysis of Hot Points and Topic Structure of Visual Culture Research in the Field of Education
}

\author{
Weidong Li ${ }^{1}$, Jingjie Zhao ${ }^{2}$ \\ ${ }^{1}$ School of Education Science, Nanjing Normal University, Nanjing, China \\ ${ }^{2}$ National Engineering Laboratory for Educational Big Data, Central China Normal University, Wuhan, China \\ Email: 396129976@qq.com
}

How to cite this paper: Li, W. D., \& Zhao, J. J. (2021). Analysis of Hot Points and Topic Structure of Visual Culture Research in the Field of Education. Open Journal of Social Sciences, 9, 186-196. https://doi.org/10.4236/jss.2021.98013

Received: June 26, 2021

Accepted: August 8, 2021

Published: August 11, 2021

Copyright (อ 2021 by author(s) and Scientific Research Publishing Inc. This work is licensed under the Creative Commons Attribution International License (CC BY 4.0).

http://creativecommons.org/licenses/by/4.0/

\begin{abstract}
Our study took 323 papers on visual culture in education field collected by $\mathrm{CNKI}$ as the research object. It extracted and counted the relevant data by Bicomb 2.0, and conducted cohesive subgroup analysis and co-occurrence analysis of key words by UCINET 6.0. Based on the analysis results, the knowledge map of visual culture research hotspots in the field of education is drawn. Finally, according to the data obtained above, the formal and content characteristics of the research literature are analyzed, which provides new ideas for the follow-up study of visual culture.
\end{abstract}

\section{Keywords}

Visual Culture, Cohesive Subgroup Analysis, Co-Occurrence Analysis

\section{Introduction}

From the end of the 20th century to the beginning of the 21st century, Chinese scholars began to introduce the newly emerging "visual culture studies" from the West in order to deal with the visual culture phenomenon under the trend of postmodernism in China. The development was short but the achievements were remarkable. There are over 600 articles related to "visual culture". In the field of education, the number of literatures on visual culture also shows an increasing trend, and different scholars pay different attention to it from different perspectives. The research content involves four different kinds of condensed subgroups. Based on this, with the help of tools such as BICOMB 2.0 and UCINET 6.0, by means of keyword clustering and co-occurrence analysis, the paper analyzes the research hotspots and topic structures of visual culture in the 
field of education in China in a visual way on the journal papers obtained from $\mathrm{CNKI}$, so as to provide reference for similar research.

\section{Research Design}

\subsection{Data Source}

Taking CNKI as the data source and "visual culture" as the topic, this paper searched a total of 634 relevant literatures belonging to the discipline of education. After secondary screening, a total of 323 valid literatures were finally selected and exported and stored locally in the format of Note First. The title, author, document organization, key words and abstract of each document are stored in the exported literature for further analysis of the literature information.

\subsection{Research Methods and Tools}

\subsubsection{Research Methods}

In this paper, two methods, keyword clustering and keyword co-occurrence, are used to analyze the research hotspots and topic structures of visual culture. Keyword clustering is the process of classifying different keywords into different classes or clusters. The keywords in the same class have great similarities, while the keywords in different classes have great differences. Coword analysis is a commonly used content analysis method, which uses modern statistical techniques to analyze the occurrence frequency of some words (generally main topics or keywords) in a certain field in the literature, and then summarizes the research hotspots in this field.

\subsubsection{Research Tools}

In this study, the authors, journals, literature institutions, publication time and keywords in the literature were statistically analyzed by the BICOMB 2.0 bibliographic co-occurrence analysis system, and the social network analysis software UCINET 6.0 was used to conduct the cohesive subgroup analysis and keyword co-occurrence. The clustering subgroup tree diagram of keywords and the keyword network analysis diagram are obtained, and then the research hotspots and topic structures of visual culture in the field of education in China are analyzed from the perspective of the form characteristics and content characteristics of the literature.

\subsection{Research Process}

The research process of this paper is mainly divided into four stages: data collection, data consolidation, data statistics and data analysis. In the data collection stage, the main work is to retrieve 634 relevant literatures from CNKI, manually delete irrelevant literatures, and export the remaining 323 valid literatures. In the data consolidation phase, the files exported in the first phase are imported into the Bibliographic co-occurrence analysis system (Bicomb 2.0) software and keywords are extracted. In the data statistics stage, we can use BICOMB 2.0 to de- 
rive the statistical table of publication time, the statistical table of issuing institution, the analysis table of literature sources, the statistical table of keyword frequency, and the co-occurrence matrix of keywords. In the data analysis stage, we mainly use UCINET 6.0 to analyze the co-occurrence matrix obtained in the third stage. The tree graph of keyword agglomeration subgroup and the keyword network analysis graph are obtained.

Bibliographic co-occurrence analysis system (Bicomb) is used to process the literature records downloaded from bibliographic databases (such as PubMed, SCI, CNKI, Wanfang, etc.). The specific functions include: 1) Extracting specific fields, such as author, journal name, title, publication date, citation, etc.; 2) Count the occurrence frequency of corresponding fields; 3) After intercepting high-frequency entries according to a certain threshold value, the co-occurrence matrix and item-source literature matrix (such as high-frequency word-paper matrix) are formed. 4) The matrix formed by output high-frequency entries and matrix (TXT documents) can be used for further cluster analysis and network analysis.

UCINET, a menu-driven Windows program, is probably the best known and most frequently used comprehensive analysis program for social network data and other similar data. The raw data that UCINET is able to process is in matrix format, providing a large number of data management and transformation tools. UCINET contains a large number of network analysis programs including cliques, Clans, Plexes and areas (Components, cores), Centrality, individual network analysis and structural hole analysis. UCINET also includes a number of process-based analysis programs, such as cluster analysis, multidimensional scaling, two-module scaling (singular value decomposition, factor analysis and correspondence analysis), role and status analysis (structure, role and regular equivalence), and fitting central-edge models. In addition, UCINET provides a variety of statistical procedures ranging from simple statistics to fitting $\mathrm{p} 1$ models.

\section{Visualization Analysis of Research Literature}

Literature features include two categories: formal features and content features of literature. The main difference between the two categories is whether they are closely related to the subject content of literature information. If closely related, it is the content features of literature; otherwise, it is the formal features of literature. The analysis of the formal characteristics of the literature helps to have a clear understanding of the research enthusiasm of a certain topic and the attention of various institutions in a certain field. The analysis of the content characteristics of the literature helps to understand and grasp the research hot spots in this field.

\subsection{Visual Analysis of Formal Features of Literature}

\subsubsection{Time Distribution of Literature}

The paper describes and predicts the development trend of the quantity of lite- 
rature in the future through the statistics and analysis of the quantity of literature of visual culture. As can be seen from the statistical data (Figure 1), the number of published articles has been increasing since 2002 when visual culture was combined with education, and the number of published articles has been at a stable stage since 2007. It can be judged that the research on visual culture in the field of education is entering a stable development stage. Visual culture in education is the educational information presented by visual teaching media, which gives educators and educates a brand new feeling, deeply affects educational concepts and habits, and should become one of the content of education research.

\subsubsection{Institutional Distribution of Literature}

In China, Nanjing Normal University, Anhui Normal University, Xuzhou Normal University, Shandong Normal University, Jiangsu Radio and Television University and East China Normal University have published many papers on visual culture, with a cumulative contribution rate of $20.51 \%$, among which the Science of Education and Science of Nanjing Normal University is the most important. School of Education Science and School of Anhui Normal University had the largest number of papers, 25 and 13 respectively. In addition, the publishing institutions are mainly distributed in colleges and universities, and most of these colleges and universities are strong normal colleges. Among them, Nanjing Normal University has launched the course "Visual Culture and Media Literacy", which mainly focuses on the exploration of the teaching practice of media literacy education in recent years. Anhui Normal University pays heed to the visual literacy education of college students in the network environment, and Xuzhou Normal University pays much attention to media literacy education. It can be seen that various institutions pay attention to the theoretical basis of visual culture and the teaching practice in the curriculum.

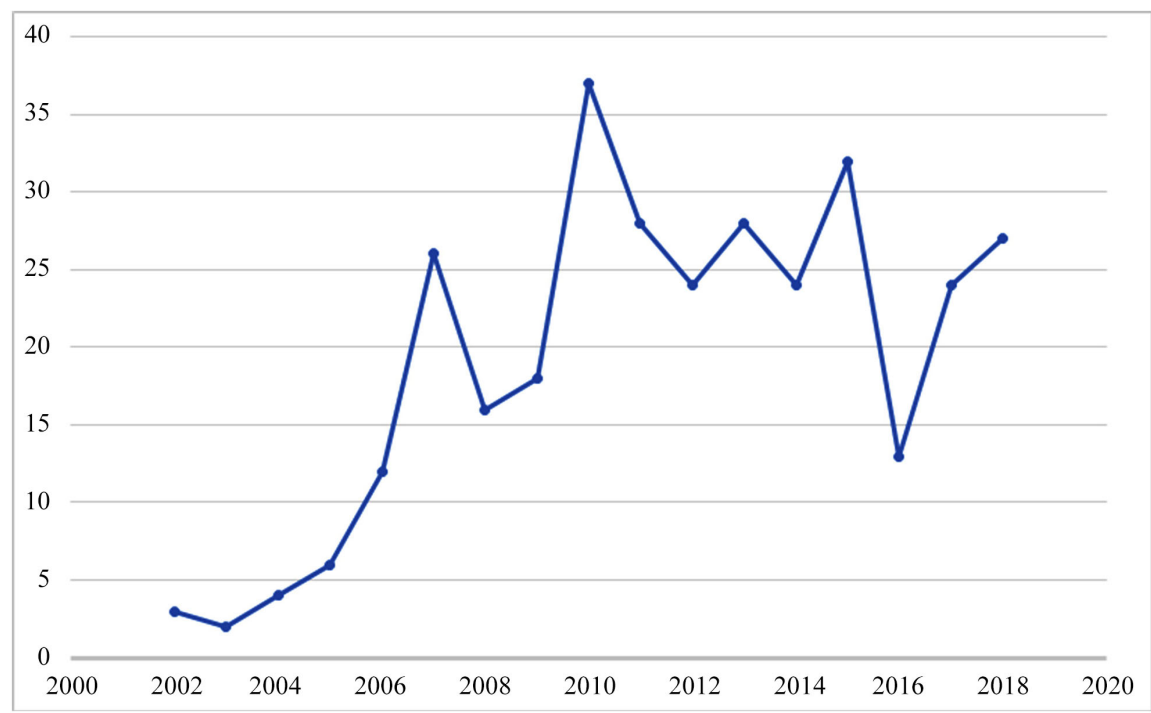

Figure 1. Time distribution of literature. 


\subsection{Visualization Analysis of Content Features of Literature}

\subsubsection{Keywords Frequency Analysis}

Keywords are the summarization of research content of literature, so the word frequency of keywords in a certain field reflects the research hotspot and main research content to a certain extent. In this paper, the BICOMB 2.0 software was used to extract a total of 24 keywords with frequency greater than or equal to 5 from 323 valid literatures, and the cumulative frequency percentage was $37.1 \%$. The top 20 keywords in frequency were listed in Table 1. Table 1 shows that in addition to "visual culture", the top 10 keywords are "visual literacy", "arts education", "educational technology", "media literacy", "art education", "ideological and political education", "visual literacy education" and "university students".

Table 1. Shows the top 20 keywords in word frequency.

\begin{tabular}{|c|c|c|c|c|}
\hline Num & Key Fields & $\begin{array}{l}\text { Word } \\
\text { Frequency }\end{array}$ & Percentage & $\begin{array}{l}\text { Cumulative } \\
\text { Percentage }\end{array}$ \\
\hline 1 & Visual culture & 229 & 18.3494 & 18.3494 \\
\hline 2 & Visual literacy & 41 & 3.2853 & 21.6346 \\
\hline 3 & Fine arts education & 33 & 2.6442 & 24.2788 \\
\hline 4 & Education technology & 18 & 1.4423 & 25.7212 \\
\hline 5 & Media literacy & 15 & 1.2019 & 26.9231 \\
\hline 6 & Art education & 13 & 1.0417 & 27.9647 \\
\hline 7 & $\begin{array}{l}\text { Ideological and } \\
\text { political education }\end{array}$ & 9 & 0.7212 & 28.6859 \\
\hline 8 & Visual Literacy Education & 9 & 0.7212 & 29.4071 \\
\hline 9 & College students & 8 & 0.6410 & 30.0481 \\
\hline 10 & Aesthetic education & 8 & 0.6410 & 30.6891 \\
\hline 11 & Education & 7 & 0.5609 & 31.2500 \\
\hline 12 & Online courses & 7 & 0.5609 & 31.8109 \\
\hline 13 & Visual Arts Education & 7 & 0.5609 & 32.3718 \\
\hline 14 & Era of reading & 6 & 0.4808 & 32.8526 \\
\hline 15 & $\begin{array}{l}\text { College ideological and } \\
\text { political education }\end{array}$ & 6 & 0.4808 & 33.3333 \\
\hline 16 & $\begin{array}{l}\text { Visual Culture } \\
\text { Communication }\end{array}$ & 6 & 0.4808 & 33.8141 \\
\hline 17 & Media Literacy Education & 6 & 0.4808 & 34.2949 \\
\hline 18 & Visual thinking & 5 & 0.4006 & 34.6955 \\
\hline 19 & Quality education & 5 & 0.4006 & 35.0962 \\
\hline 20 & Visual arts & 5 & 0.4006 & 35.4968 \\
\hline
\end{tabular}




\subsubsection{Key Words Cohesive Subgroup Analysis}

In order to further understand the theme structure of visual culture research, the keywords with close connection and high similarity are divided into corresponding categories. In this paper, the keyword with higher frequency is cohesive subgroup analysis (Cohesive Subgroups). From the perspective of social network analysis, cohesive subgroup is a subset of actors in which the actors have relatively strong, close, direct, frequent or positive relationships. In this paper, Concacor method in UCINET software is used to analyze condensed subgroups. Concor is an iterative correlation convergence method. It is based on the fact that if you repeat the calculation of the correlation coefficients between the rows (or columns) in a matrix, you will end up with a matrix of correlation coefficients consisting only of 1 and -1 . After several iterations, Concor uses a tree diagram to express the degree of structural equivalence between locations and to mark the network members owned by each location. In this paper, the tree diagram generated after the condensation subgroup analysis of the keywords is shown in Figure 2.

According to the classification of the first branch of the tree, these keywords can be divided into four categories.

Category 1: consists of visual culture, visual thinking, media literacy education and visual cultural communication. Among them, visual culture is an independent sub-branch, and the other branch consists of visual thinking, media literacy education and visual culture communication. Visual thinking is an important link in media literacy education. Visual thinking is divided into associative thinking, reverse thinking and divergent thinking (Zhang, 2007). Jiang Zhaoyuan

Visual Culture
Visual Thinking
Media Literacy Education
Visual Culture Communication
Visual Culture Age
Visual Culture Course
Colleges
Education Technology
Media Literacy
School Art Education
College Students
Visual Literacy Education
Figure-reading
Visual Literacy
Teaching Design
Fine Arts Education
College Ideological and Political Education
Online Courses
Quality Education
Visual Arts
Visual Arts Education
Art Education
Ideological and Political Education
Impact
Fine Arts Teaching
Aesthetic Education
Education Value
Postmodernism
Art Appreciation
Education
Culture
Fine Arts

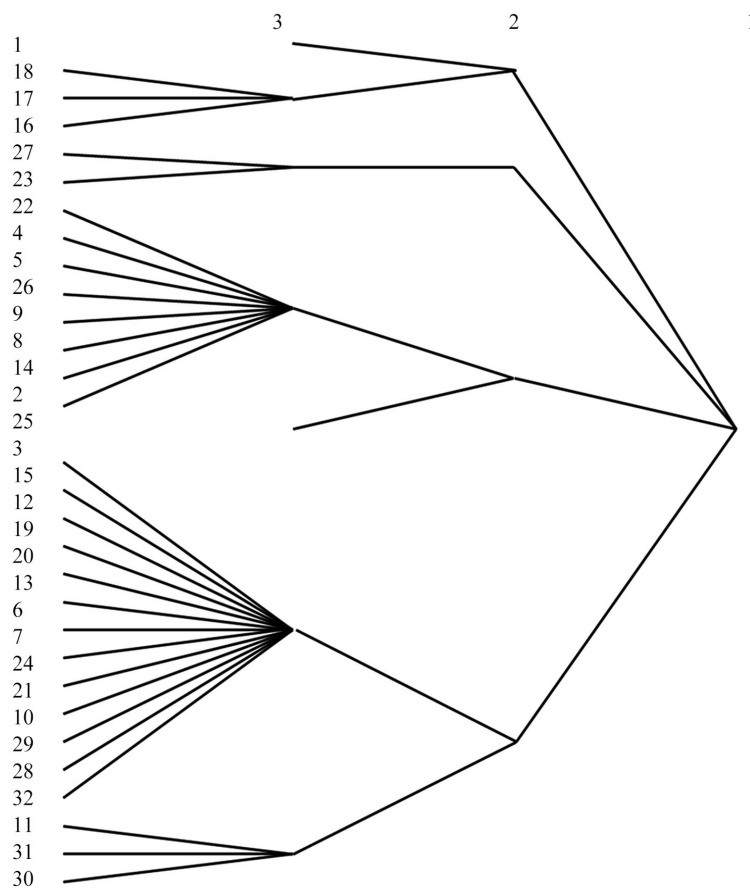

Figure 2. Condensate subgroup analysis tree diagram. 
believes that in the context of visual culture era, traditional thinking of fine art education needs to be changed and take visual nature as the main line and give distinctive humanistic spirit of the times so as to cultivate students' visual literacy and construct visual aesthetics, meaning and the ability to express visual images of independent thinking (Tang \& Geng, 2018). Media literacy education serves the communication of visual culture. For example, Xu Chunling suggested that teachers' media literacy should be improved so that they can make full use of various resources, and media literacy education should be listed as lifelong education to enhance the effect of visual culture communication $(\mathrm{Xu}$, 2013).

Category 2: consists of visual culture times and visual culture courses. With the development of the network as well as the spread of electronic equipment, film, television, advertising, photography, image design and so on, human has entered the "era of picture reading", visual culture has become our mainstream culture. However, in the era of visual culture, the popularization and vulgarization of visual culture not only brings people aesthetic pleasure, but also makes people feel at a loss. Therefore, Weng Lifen believes that the teaching of visual art appreciation should be popularized in the context of chaotic cultural trend, disappearance of classical culture and unclear dominant culture (Kuang, 2018). From this, in the era of visual culture, visual culture needs to keep pace with the times, and visual culture courses should be opened correspondingly to help to understand the concepts, methods and objects in the era of visual culture so that people can change from passive acceptance to active acquisition of image culture.

Category 3: mainly includes universities, educational technology, media literacy, school art education, college students, visual literacy education, picture reading era, visual literacy and instructional design. This category mainly focuses on the target audience and majors of visual culture and theoretical basis and teaching strategies in visual literacy education. From the perspective of the target audience of visual culture, Chinese scholars' research on education under visual culture mainly focuses on college students. For example, Yang Tingting analyzed the challenges and countermeasures of visual culture to the ideological education of college students (Zhao, Wen \& He, 2013), and Liu Yuhuan studied the development and application of visual literacy education resources for college students under the concept of "well-informed" (You, 2021). From the selected keywords of "educational technology", it can be seen that educational technology has the largest number of visual culture researchers' majors. Many schools, such as Nanjing Normal University and Anhui Normal University, set the direction of visual culture under the major of educational technology. Scholars also have lots of research of teaching strategies of visual culture course, for instance, Zhang Shuyu considered that the thought of curriculum teaching design is embodied in three aspects: one is the combination of theoretical basis and practical experience in content, the second is the reasonable classification of the content module and guidance in structure, the third is formally highlighting 
the three-dimensional multimedia courseware (text ++ project site) (Nie, 2020). Bao Yingying combined the domestic and foreign related research achievements of theory and practice of the flipped course, on the basis of hybrid learning, mastery learning and theory leaening using the designed research method to comprehensively analyze characteristics of both the course and the learners to arrange the flipped classroom of visual culture and to put it into action (Domínguez \& Jelena, 2021). Zhao Huichen and others divided the integration of visual technology and curriculum into teaching resources, teaching behavior and teaching theory according to the three levels of culture including objects, behaviors and institutions, and carried out an analysis. At the level of objects, visual resources of course teaching should be constructed, and at the level of behavior, visual teaching behavior of course should be carried out. At the institutional level, the visual teaching theory of the curriculum must be formed (Yin, 2020).

Category 4: consists of two sets of keywords subgroup setting the fine arts education, the ideological and political education, network curriculum and quality education, the visual arts, visual arts education, art education, the ideological and political education, impact, art teaching, aesthetic value, postmodernism and art appreciation for the first subgroup and education, culture, art as the second subgroup. It can be seen from Figure 2 that the first subgroup focuses on ideological, political and art, and category 4 can be summarized as related research on ideological and political education and art education under visual culture. In the aspect of ideological and political education, Chinese scholars put forward the teaching principles and methods of ideological and political education in the context of visual culture. For example, Kuang Heping proposed four teaching principles in terms of ideological, directional, theoretical and subjectivity based on the nature, function, characteristics and rules of ideological and political education (Zhang, 2012). Wei Xiaojun et al. proposed teaching methods suitable for the era of visual culture, and suggested that colleges and universities explore the realization of path of visual culture in ideological and political education from four aspects: strengthening visual "check", cultivating visual literacy, attaching importance to visual culture and constructing visual ethics (Yang, 2018). In the aspect of art education, Chinese scholars also put forward some new teaching methods. For example, Zhao Yong believes that in art appreciation teaching, multimedia assisted teaching and network teaching should be emphasized, as well as collaborative discussion and cooperative learning using information platform and digital resources (Bao, 2017). Yang Jinsong put forward four concrete measures: Firstly, viewing the general education as the foundation without artificially setting up barriers between subjects and ideas; Secondly, cultivating visual cultural judgment and extending classroom teaching to the society; Thirdly, putting the cultivation of innovation ability on the basis of the wisdom of different fields, such as nature and society, instead of only paying attention to the integration of knowledge (Jiang, 2015). 


\subsubsection{Co-Occurrence Analysis}

Through the analysis of the keywords of condensing subgroup, we can learn about domestic thematic structure and the main research hotspot in the research of the visual culture, but there is no way to clear the relationship between the literature and research intersection, so it is necessary for co-occurrence analysis of keywords to demonstrate the connection between the theme and its keywords for further analysis of the current research status and hotspot of deep learning. In this paper, the keyword co-occurrence matrix exported by BICOMB 2.0 was imported into UCINET 6.0 software, and the NetDraw tool was used to draw the keyword network analysis diagram, as shown in Figure 3.

In the keyword co-occurrence diagram, the square node represents the keyword. The larger the node is, the greater the role of the keyword in the network, the stronger the ability to control the emergence of other keywords; and the closer the node is, the closer the connection is.

It can be seen in the Figure 3: the relation between each keyword is complicated, and keywords are closely linked with the largest node retrieval keywords "visual culture" as the center, and "the fine arts education", "visual literacy", "art education" as well as "media literacy" education technology and other keyword nodes are at close range with a "visual culture". Though far from the center, "Visual culture course" and "Visual literacy education" are important topics in the study of visual culture, which plays an important role in cultivating and improving students' visual literacy and media literacy. In addition, visual literacy, instructional design and fine arts education have larger nodes, indicating a greater influence on the study of visual culture.

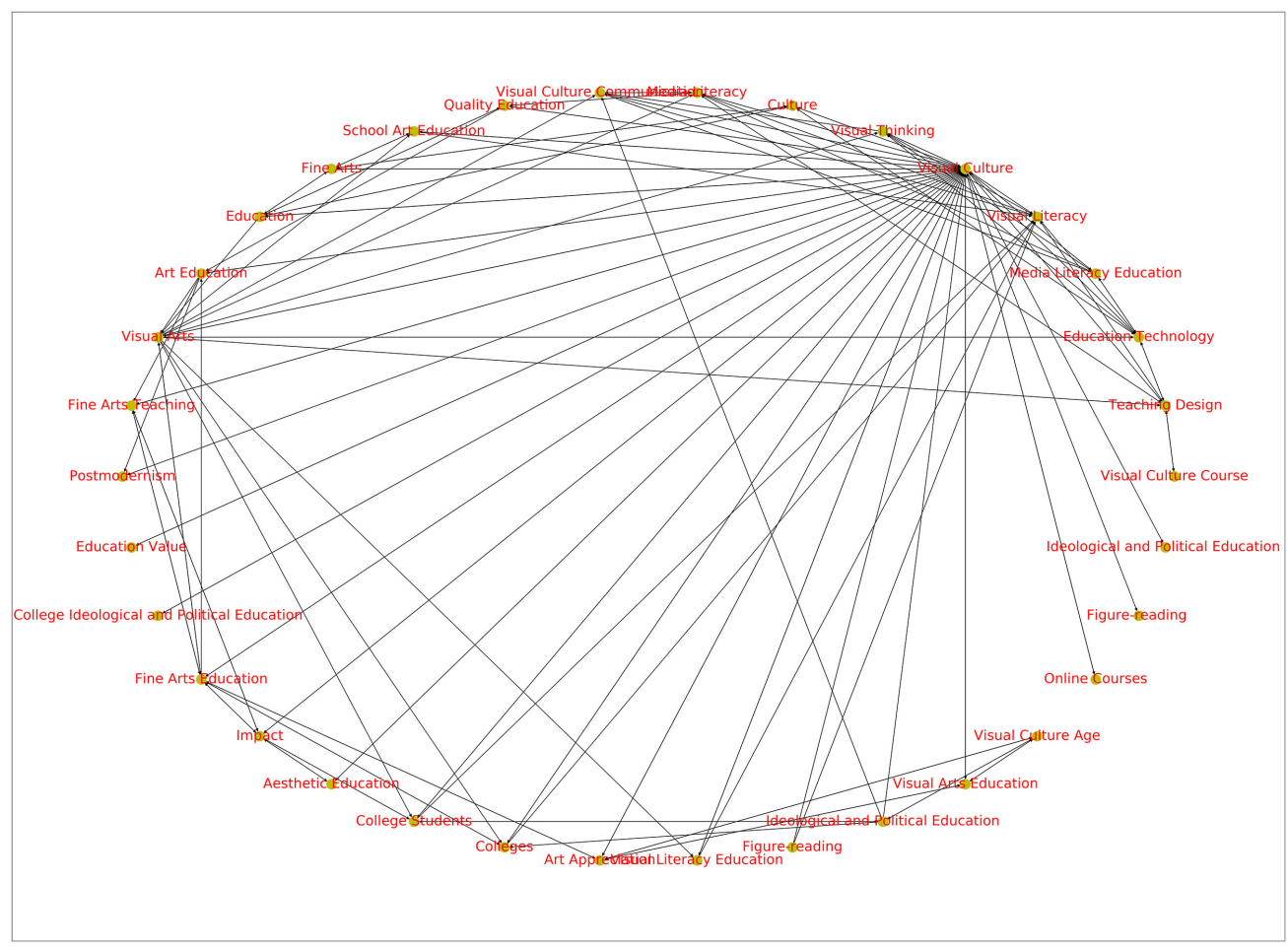

Figure 3. Keyword network analysis diagram. 


\section{Conclusion}

Through the analysis above, the focus of visual culture research in the field of education in China includes: 1) Currently, the object of visual culture research focuses on universities and college students; 2) It is an important research topic to cultivate students' visual literacy and media literacy; 3) There are many researches in the aspects of the ideological and political education and art education on visual culture.

The theme structure of visual culture research is as follows: 1) Visual thinking is closely related to media literacy education and visual culture communication, media literacy is closely related to visual literacy; visual art, quality education and network courses are closely related; 2) In the study of visual culture, visual literacy, instructional design and fine arts education have a great influence, and "fine arts education", "visual literacy", "art education", "media literacy", "educational technology" and other keywords are most closely related to visual culture. The conclusions can provide new ideas and references for the follow-up research on visual culture.

\section{Conflicts of Interest}

The authors declare no conflicts of interest regarding the publication of this paper.

\section{References}

Bao, Y. Y. (2017). Application Research of Flipped Classroom in Visual Culture Curriculum. Master's Thesis, Nanjing Normal University.

https://kns.cnki.net/KCMS/detail/detail.aspx?dbname=CMFD201801\&filename $=10172$ 82135.nh

Domínguez, R. E., \& Jelena, B. (2021). Exploring Critical and Visual Literacy Needs in Digital Learning Environments: The Use of Memes in the EFL/ESL University Classroom. Thinking Skills and Creativity, 40. https://doi.org/10.1016/j.tsc.2020.100783

Jiang, Z. Y. (2015). The New Choices of Art Education in the Age of Visual Culture. Journal of Tianjin Academy of Fine Arts, No. 4, 90-91.

Kuang, H. P. (2018). The Teaching Principle of "Concretization" for Ideological and Political Theory Courses in Colleges and Universities under the Background of Visual Culture. Modern Education Science, No. 7, 50-53+75.

Nie, Q.-J. (2020). On the Improvement Path of College Students' Aesthetic Quality Education by Reading Literary Classics in the Context of Visual Culture. Journal of Qingdao Technical College, No. 6, 36-39.

Tang, C.-H., \& Geng, T.-T. (2018). An Exploration of the Practical Mode of Preschool Art Education in the Visual Context. Hundred Schools in Arts, No. 1, 194-198+250.

$\mathrm{Xu}$, C.-L. (2013). Implementing Strategies of Media Literacy Education for University Teachers. Journal of Jixi University, No. 3, 8-9+13.

Yang, T. T. (2018). Challenges and Countermeasures of College Students' Ideological Education on Visual Culture. Journal of Anhui Polytechnic University, No. 6, 45-49.

Yin, S. (2020). Innovation and Exploration of Visual Thinking Mode in Visual Communication Design. Packaging Engineering, No. 4, 291-293+311. 
You, J. (2021). Research on the Application of Innovative Thinking in Visual Communication Design Teaching in Colleges and Universities. Journal of Educational Research and Policies, No. 1.

Zhang, B. (2007). Exploration and Analysis on Visual Culture Art Education in the Postmodernism Atmosphere. Studies in Foreign Education, No. 8, 58-61.

Zhang, S. Y. (2012). Key Concepts and Teaching Design of the Course Visual Culture \& Media Literacy. Modern Distance Education Research, No. 2, 38-43.

Zhao, H. C., Wen, J., \& He, Y. T. (2013). Model Construction and Implementation of the Integration between Visual Technology and Curriculum from the Perspective of Visual Culture. Journal of Distance Education, No. 2, 66-72. 